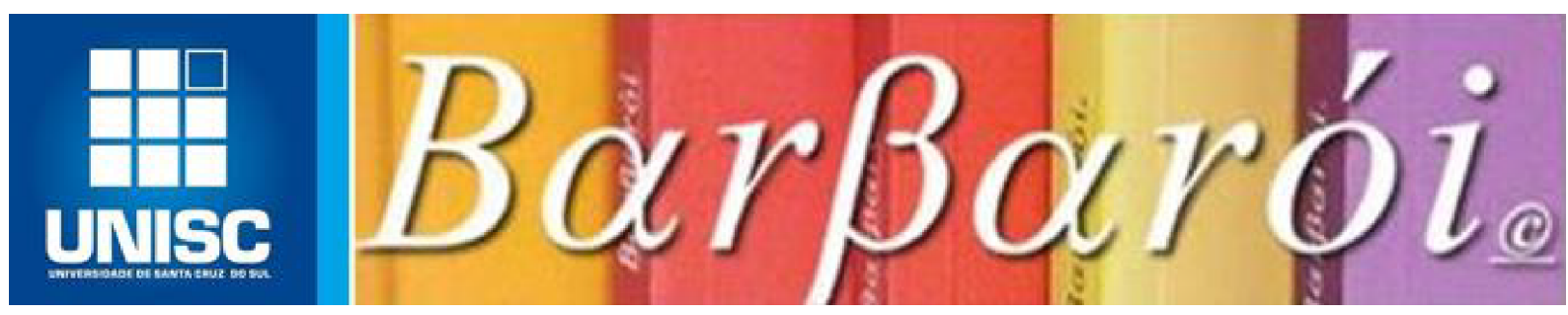

\title{
A FILOSOFIA E AS HUMANIDADES NA FORMAÇÃO UNIVERSITÁRIA.
}

DOI:http://dx.doi.org/10.17058/barbaroi.v0i59.16985

\author{
$*$ \\ Sérgio Schaefer \\ Entrevistado - Universidade de Santa Cruz do Sul - UNISC - Brasil \\ César Hamilton Brito de Goes \\ Entrevistador - Universidade de Santa Cruz do Sul - UNISC - Brasil \\ Marco André Cadoná \\ Entrevistador - Universidade de Santa Cruz do Sul - UNISC - Brasil
}

\section{Resumo:}

A entrevista aborda temas como a importância da filosofia e das ciências humanas na formação universitária. A partir de um resgate da trajetória do professor Sérgio Schaefer na Universidade de Santa Cruz do Sul, na condição de professor de Filosofia, a entrevista levanta questões sobre a experiência de construção de uma universidade comunitária, das lutas pelo reconhecimento de espaços de formação para a filosofia e para as ciências humanas nas diferentes áreas do conhecimento, sobre os desafios colocados em tempos de transformações tecnológicas e de afirmação de caminhos pragmáticos no campo da educação para o pensar e o fazer filosofia na Universidade.

\section{Palavras-chave:}

UNISC, formação universitária, filosofia, ciências humanas, filosofia e ciências humanas na Universidade.

\section{Entrevistadores:}

Sérgio. Você se desvinculou da UNISC recentemente, em 2016, e sabemos que a partir de então, além de sua dedicação à família, ao cuidado de seu sítio, às conversas com amigos, 
também dedica seu tempo para a produção literária. Gostaríamos que nos falasse um pouco sobre essa produção.

\section{Sérgio Schaefer:}

O meu primeiro romance, Zé Divino, o messias, publicado pela Civilização Brasileira, em 1976, foi escrito em Nortelândia, no Mato Grosso, quando lá morei e trabalhei por oito anos como professor do ensino fundamental e médio entre os garimpeiros. Em 1989, já residindo em Venâncio Aires, saiu o segundo romance, Rosas do Brasil, publicado pelo Instituto Estadual do Livro/RS. Em 2001, publiquei o romance $O$ gaudério Macunaíma e a pititinga macia de Brunilde, pela Editora Mercado Aberto em coedição com a Edunisc. Nos anos seguintes, sucederam-se várias publicações: o livro de contos, Sombras (2006), pelo Instituto Estadual do Livro; o romance $O$ rio de Heráclito (2008), pela Editora Revolução Cultural; outro livro de contos, $O$ artista quando velho (2014), também pelo Instituto Estadual do Livro. No ano de 2017, um ano muito produtivo, logo após a minha aposentadoria na UNISC, publiquei quatro livros: o romance Gumercindo Nunes e o Mouro, o romance As quatro cartas, a novela satírica $A$ carta paralela. Os dois primeiros foram publicados pela Editora Metamorfose, de Porto Alegre, e o terceiro pela Editora Gazeta, de Santa Cruz do Sul. Ainda em 2017, publiquei pela Editora Traço, de Venâncio Aires, o poema satírico Os ratos, que trata do governo golpista de Temer. Recentemente (2019), e esta é a minha última produção, publiquei pela mesma Editora Traço o poema satírico A peste, que trata do pestilento governo Bolsonaro.

Tenho também alguns ensaios publicados: A lógica dialética, um estudo da obra filosófica de Caio Prado Junior (1985), pela Editora Movimento, de Porto Alegre; O conhecimento popular (1993), pela Editora Vozes (coautor Ari Paulo Jantsch). Sou autor de textos e coorganizador das seguintes coletâneas: Drummond e a filosofia (2007), pela EDUNISC; Caetano e a filosofia (2010), pela EDUNISC e Editora da Universidade Federal da Bahia; $O$ cinema brasileiro e a filosofia (2012), pela Editora da Universidade Federal de Uberlândia; $O$ samba e a filosofia (2015), pela Editora Prismas. A minha tese de doutorado na UFRGS, $A$ teoria estética em Adorno, publicada em formato digital, até este momento recebeu 12.324 downloads, no Brasil e em vários países.

\section{Entrevistadores:}

E nesse trabalho literário, mas também no trabalho filosófico, quais são suas principais referências intelectuais?

Barbarói, Santa Cruz do Sul, n.59 - número especial, p.<174-193>, Ago./Set. 2021 


\section{Sérgio Schaefer:}

No campo da Filosofia sempre gostei do confronto entre a dialética e a metafísica. Enquanto a primeira procura entender os movimentos e as mudanças da realidade, construindo certos conceitos dinâmicos, a segunda procura resolver os movimentos e as mudanças em conceitos estáticos. Existem duas razões principais que fazem a metafísica direcionar seus esforços teóricos para a estaticidade conceitual: pretender dar firmeza (aparente) ao conhecimento e fugir da regressão linear ao infinito. A ideia de Deus, por exemplo, é uma ideia metafísica. Essa ideia é concebida como uma causa final (ou primeira) do universo. Bem parecida com a ideia aristotélica do Motor Imóvel, causa final (ou primeira) de todos os movimentos.

Tanto a ideia de Deus como a ideia do Motor Imóvel pretendem pacificar o nosso conhecimento e imobilizá-lo. Mas ambas as ideias permitem deflagrar o confronto entre o ser e o nada, aquilo que é e aquilo que ainda não é. Este é o ponto de partida da dialética. Por exemplo, Deus é o ser que, do nada, tudo cria; o Motor Imóvel é o ser-motor, que, da imobilidade, tudo movimenta. Em última instância, na metafísica está a semente da dialética, fechada em si mesma, com medo de frutificar.

Para entender isso dediquei muitos esforços teóricos na compreensão dos filosofares de Platão, Aristóteles, Hegel, Marx, Adorno e outros pensadores, tendentes ou para a metafísica ou para a dialética.

No campo das Letras ou da Literatura, desde meus tempos das leituras mais organizadas, sempre gostei e admirei autores que conseguem escapar do usaico, do senso comum. Entre eles, cito dois meus preferidos: Guimarães Rosa e James Joyce. Escapar do usaico, na literatura, significa não só escrever de forma diferente ou narrar de forma diferente algum enredo, mas principalmente - e isso, para mim, é o importante - propor, através da arte literária, a mudança. Quando Guimarães Rosa e Joyce, por exemplo, criam estranhos neologismos, eles estão sugerindo que as mudanças podem acontecer não somente no papel, mas na realidade concreta que cerca os leitores. A diferença apresentada no neologismo ou na estrutura da frase ou no andamento do plot é indicativa de que a realidade pode ser diferente do que é.

Quando a arte imita por semelhança, ela está sugerindo que a realidade não precisa mudar ou se tornar diferente. Quando a arte (seja a literária, a pictória, a musical etc.) propõe a não imitação pela semelhança, ela está, de fato, propondo a diferença.

Barbarói, Santa Cruz do Sul, n.59 - número especial, p.<174-193>, Ago./Set. 2021 


\section{Entrevistadores:}

Qual a relação entre a Filosofia e a Literatura na sua experiência de professor e escritor? Essa relação existe?

\section{Sérgio Schaefer:}

Não faço um relacionamento direto entre Literatura e Filosofia. Se bem que a minha Literatura tem influência da Filosofia, ela não tem vinculação direta. $\mathrm{O}$ fazer literário é uma invenção minha, nasce do meu imaginário. É fruto daquilo que eu gosto de escrever. Eu penso um assunto, se é do meu agrado passo a colocá-lo no papel.

\section{Entrevistadores:}

\section{Literatura e Filosofia surgiram juntas na sua experiência?}

\section{Sérgio Schaefer:}

Não, a Filosofia surgiu antes. Graduei-me em Filosofia. Quando escrevi e publiquei o primeiro livro, Zé Divino, o messias, morava em Nortelândia, no Mato Grosso, já com o curso de Filosofia pronto. Lá, no meio de garimpeiros e daquela vida diferente, surgiu a ideia de escrever a história de um personagem meio milagreiro, uma espécie de reformador. Esse foi o meu primeiro livro de literatura. Não tinha nada a ver com a Filosofia. Tinha a ver, sim, com a situação social do lugar onde eu estava vivendo naquele momento.

Por outro lado, aproveitando para acrescentar algo à questão feita anteriormente sobre a relação entre Filosofia e Literatura, é possível fazer uma relação da história do Zé Divino com a filosofia latino-americana da libertação do Enrique Dussel, que conheci e estudei no curso de Filosofia. Nós estudamos a filosofia da libertação. Isso pode, sem dúvida, ter influenciado na escolha do tema do Zé Divino. O conhecimento de temáticas filosóficas pode sugerir temáticas literárias.

O que eu mais gosto de fazer, em Literatura: sátiras, paródias e metaliteratura. Isso não tem a ver, basicamente, com o filosofar. A Filosofia, no seu cerne, não é satírica nem paródica, ela é essencialmente conceitual. Constrói, reconstrói, faz, desfaz conceitos no interior de um campo teórico. Gosto de satirizar, de parodiar, de retrabalhar outros autores. Os ratos, A peste - são sátiras. O livro sobre o descobrimento do Brasil, A carta paralela, é uma sátira. Gosto muito de fazer metalinguagem, metaliteratura. Rosas do Brasil é metaliteratura, é um romance sobre os romances e as novelas de Guimarães Rosa, com algum toque satírico, meio crítico. $\mathrm{O}$ mesmo faço com $O$ gaudério Macunaíma e a pititinga macia de Brunilde, que é metaliteratura do Macunaíma de Mário de Andrade. O que eu posso dizer é que a minha literatura é influenciada indiretamente pela filosofia. Não trabalho conceitos teóricos na Barbarói, Santa Cruz do Sul, n.59 - número especial, p.<174-193>, Ago./Set. 2021 
literatura, esse não é seu papel. Também não é papel da literatura ensinar, dar lições de moral. A literatura pode brincar com as palavras, lutar com elas como dizia o Drummond, ressignificá-las, pode brincar com os conceitos do nosso cotidiano, reconceituá-los, pode brincar com as frases, com as vírgulas, com os pontos, pode reenredar enredos que acontecem nas vivências e convivências humanas e inter-humanas. E pode ser crítica, sim. Isso, para mim, é a literatura.

Mas não uma literatura de senso comum, isso não. Como já disse, fujo do usaico que muitas vezes aparece na literatura. Para mim, literatura tem que ter uma proposta de mudança. É preciso escrever de tal modo que o leitor, quando está lendo, perceba "poxa, eu tenho que mudar alguma coisa, não sei o quê, mas tenho que mudar". Nunca escreveria assim: "Tem que mudar as coisas no Brasil, tem que derrubar o Bolsonaro". Sem cair no usaico e sem nenhum direcionamento autoritário, escreveria sobre o que o Bolsonaro está fazendo. O leitor - talvez, pode ser, quem sabe - chegaria a pensar "poxa vida, o governo Bolsonaro está acabando com o Brasil" e, então, começar a pensar em alguma mudança.

Aprendi isso com os bons escritores. Basta ler, por exemplo, as obras de Guimarães Rosa e James Joyce. Guimarães Rosa, em Grande sertão: veredas, conta uma história, mas, em outras palavras, está dizendo: "tem que mudar esse país do jeito que ele está descrito na minha história". O leitor chega a essa conclusão ou, melhor, pode chegar a essa conclusão. James Joyce é mais difícil de ler do que Guimarães Rosa, mas quem leu Ulisses, por exemplo, também pode chegar a essa conclusão. E como James Joyce e Guimarães Rosa fazem para que isso aconteça nos seus leitores? Eles dizem que é para mudar o mundo ou alguma estrutura da sociedade? Não. Eles mudam e remudam as palavras, neologizam, ressignificam. Mudar as palavras, de um ponto de vista literário, é indicativo de mudança de alguma coisa. A arte literária consciente e crítica faz isso. A pintura também e também a música. E outras artes também.

\section{Entrevistadores:}

Também nos interessa conhecer um pouco sobre sua trajetória na UNISC. Em que momento você chega na UNISC e hoje, depois de um longo tempo na Instituição, quais são as experiências mais significativas para você?

\section{Sérgio Schaefer:}

Entrei na UNISC em 1982, quando ainda era FISC (Faculdades Integradas de Santa Cruz). Comecei a trabalhar os conteúdos de Filosofia nos cursos de Pedagogia e Ciências Sociais. Quando houve a mudança para o campus atual, além de continuar dentro desses cursos, Barbarói, Santa Cruz do Sul, n.59 - número especial, p.<174-193>, Ago./Set. 2021 
comecei a trabalhar em outros cursos. Naquele momento, a UNISC chegou a considerar que a Filosofia era importante em outros cursos, como Economia, Administração e Ciências Contábeis. Mais tarde, trabalhei nos cursos de Psicologia e de Direito. E, claro, no curso de Filosofia, que não teve longa existência na instituição, mas que, para mim, trabalhar nesse curso, foi uma das melhores experiências pedagógicas. Certamente, porque era o meu campo de formação específica.

Tratar conteúdos filosóficos e discutir questões que foram importantes ao longo da história da Filosofia sempre foi uma experiência significativa para mim. Isso, em qualquer curso onde atuei. De um modo especial, duas problemáticas eram tratadas com maior atenção nas minhas aulas: a problemática do conhecimento e a problemática ética.

Questões relacionadas ao conhecimento também foram tratadas por mim em cursos de formação para os colegas professores da UNISC: como construímos os conceitos, como os modificamos, qual é a lógica por trás dos conceitos já estabelecidos, até que ponto os conceitos ainda têm ou não têm serventia dentro da formação acadêmica. Essa era a minha proposta. Eu achei uma experiência muito interessante, pena que ela terminou. Quer dizer, terminou por um tempo. Recomeçou mais tarde, em novo formato, com palestrantes convidados de outras instituições, principalmente.

Outra experiência significativa foi a minha atuação nos Cursos de Férias - as ditas Licenciaturas Curtas - para professores de escolas estaduais e nos cursos chamados PARFOR, de aperfeiçoamento para professores de escolas públicas, programa colocado em prática no país pelos governos do PT. Por vários anos, durante as férias letivas da universidade, estava dando aula nos cursos de férias e, depois, no PARFOR.

\section{Entrevistadores:}

Você chegou a participar da discussão inicial sobre a criação do curso de Filosofia na UNISC?

\section{Sérgio Schaefer:}

Sim, fiz parte do grupo que estruturou o curso. Além de mim, formavam o grupo o prof. João Pedro, o prof. Inácio, o prof. Edgar. Não sei se esqueci de mais alguém. Me escolheram para apresentar a proposta do curso no Conselho da Universidade. Nossa proposta foi aprovada e o curso começou a funcionar logo no semestre seguinte com 19 alunos, se não me engano. Pena que esse curso foi cancelado pela Universidade. Era um curso muito bom, eu gostava de trabalhar nele, os alunos também gostavam da Filosofia. O problema é que, a cada vestibular, diminuíam os interessados.

Barbarói, Santa Cruz do Sul, n.59 - número especial, p.<174-193>, Ago./Set. 2021 


\section{Entrevistadores:}

Num determinado período o curso de Filosofia esteve muito próximo de necessidades de formação da Igreja Católica. Muitos seminaristas católicos passaram pelo curso. Como foi a relação com a Igreja Católica? Em algum momento essa relação implicou discussões sobre a formação, no sentido de aproximá-la das expectativas da religião?

\section{Sérgio Schaefer:}

Que eu saiba, nunca houve interferência das autoridades religiosas na nossa atividade didática ou pedagógica no curso de Filosofia. Os professores tinham completa liberdade de discutir do jeito que quisessem. Eu, por exemplo, cheguei a discutir as famosas provas da existência de Deus de Tomás de Aquino insistindo nos enganos lógicos que as sustentam. Talvez isso pode ter contribuído para algum seminarista desistir de ser padre. Vários dos que participavam de nossas aulas, desistiram. Não sei, pode ser. A Filosofia, quando bem discutida, bem entendida e criticamente estudada, é poderosa. Ela consegue criar um ambiente teórico interno apto a superar o senso comum e concepções equivocadas da realidade.

\section{Entrevistadores:}

Em torno da filosofia se formou uma "comunidade de filósofos" na UNISC. Em algum momento o número de professores de Filosofia no Departamento chegou aos sete, oito.

\section{Sérgio Schaefer:}

Sim, éramos oito professores, o que pode ser considerado um número significativo no interior das estruturas da UNISC e do Departamento de Ciências Humanas. Além das atividades didático-pedagógicas em sala de aula, chegamos a realizar Seminários e Colóquios de Filosofia. Sobre a felicidade, para citar um, organizado pela prof ${ }^{a}$ Suzana Albornoz, que, naquela época, era nossa colega. Funcionários e professores da instituição participaram e era aberto para o público em geral. As salas onde esses eventos aconteciam enchiam de participantes. Esses Seminários também geraram publicações.

\section{Entrevistadores:}

Considerando essa sua experiência enquanto professor de Filosofia na Universidade, gostaríamos de ouvir você sobre a questão da "tradução" dos saberes das ciências humanas em outras áreas do conhecimento. Nós sabemos que essa é uma questão importante, em especial na sala de aula, quando, afinal, os professores (de Filosofia, mas, também, de Sociologia, de Antropologia, de Política) precisam promover aproximações de suas reflexões

Barbarói, Santa Cruz do Sul, n.59 - número especial, p.<174-193>, Ago./Set. 2021 
com as outras áreas de conhecimento, mas, também, com as expectativas que os próprios estudantes têm acerca da formação universitária.

\section{Sérgio Schaefer:}

Penso o seguinte sobre essa questão: como uma das principais tarefas da Filosofia é esclarecer conceitos já estabelecidos na história do pensamento (mas não é a única tarefa!), então ela precisa discutir os conceitos mais relevantes de cada curso. No curso de Direito, por exemplo, um dos conceitos básicos é o conceito de justiça. Como o conceito de justiça é um conceito binário, é preciso trazer para a discussão o conceito de injustiça. Essa discussão, por sua vez, vai permitir rever o conceito histórico de igualdade, que também é binário, e isso leva à discussão da desigualdade. Antes de entrar nessas discussões, é fundamental que o aluno entenda bem a questão lógica da binariedade e essa discussão leva a rever o tema do senso comum na marcha do pensamento. E assim vai. Dei esse exemplo para mostrar que a Filosofia, quando trabalhada em algum curso que não seja o curso de Filosofia, deve focar sua atenção nos principais conceitos que sustentam o saber daquele curso. Ao tratar desses conceitos, o professor pode resgatar a diversidade de abordagens que se sucederam na história do pensamento em torno de determinado conceito. Platão e Aristóteles tinham uma concepção própria a respeito da justiça; a filosofia cristã escolástica tinha outra; Hegel, outra; Marx, outra. Uma boa pergunta para ser respondida então é essa: por que concepções diferentes para um mesmo conceito? Pronto, mais um vasto campo de discussão se abre para o professor e os alunos. Novamente, o professor precisa discutir a binariedade diferença/semelhança, que normalmente está na base de toda a construção de conceitos.

Assim como no caso do Direito, nos demais cursos a proposta de discussão e reflexão sobre conceitos é parecida. No curso de Psicologia, onde trabalhei por vários anos, além de discutir o par conceitual básico consciência/inconsciência, entre outros, fazia uma vinculação com os grandes pensadores da Psicologia como Freud ou Jung. No curso de Pedagogia, vinculava a discussão com o pensamento de Paulo Freire ou com outros grandes pedagogos. Pronto, o campo se abre. Entre outras sugestões paulofreireanas, a questão da ressignificação das palavras é fundamental. Temas como significado, signo, sentido, ideologia, massificação comunicacional, dominação pela linguagem e pelos significados das palavras, alienação etc. podem ser retomados e discutidos. No curso de Economia entra o velho Marx, o velho Hegel, o velho Adam Smith e por aí. Conceitos como trabalho, valor, dinheiro, exploração, mais-valia etc. podem ser trabalhados e retrabalhados. Posso dizer que os alunos da Economia gostavam das aulas assim como eu gostava. Mas em alguns cursos a coisa é mais complicada. Por exemplo, nas Ciências Contábeis (nos últimos anos, o curso eliminou a Filosofia de sua

Barbarói, Santa Cruz do Sul, n.59 - número especial, p.<174-193>, Ago./Set. 2021 
grade curricular). Uma das saídas que encontrei quando eu trabalhei Filosofia nesse curso foi através do campo das relações quantitativas. Penso que o conceito de quantidade e seus correlatos talvez seja a melhor porta de entrada para refletir filosoficamente nesse curso. Mesmo assim, os alunos não se animaram muito com as discussões e reflexões desenvolvidas. Como nas Contábeis, trabalhar Filosofia nas áreas das ciências exatas é bastante difícil. Normalmente, o professor não consegue criar um ambiente de empatia teórica com os alunos. Creio que a Sociologia ou a Ciência Política conseguiriam isso com mais facilidade, pois podem vincular a reflexão sociológica ou política com mais proximidade aos conceitos das exatas. Não sei se é isso mesmo, mas penso assim.

Trabalhei com alunos da Matemática, com alunos de Biologia, com alunos das Engenharias, mas nunca deu muito certo, quero dizer, eu não me senti muito bem como professor e os alunos não se sentiram muito bem como alunos. Não por falta de empatia pessoal e, sim, por falta de empatia teórica.

Já o curso de Comunicação é diferente dos outros. Trabalhei vários semestres nesse curso. Os alunos da Comunicação são muito festeiros, inclusive quando procuram entender os conceitos filosóficos. Para eles seria mais interessante discutir um conceito - por exemplo, ideologia numa roda de bar do que na abstêmia sala de aula. O problema é que a sala de aula não é o bar. No fim de contas, a discussão e a reflexão enveredam para a superficialidade. Para mim, o curso de Comunicação Social sempre foi o curso mais próximo da superfície teórica. Apesar de eu gostar de trabalhar com esses alunos. Você conseguia chamar a atenção e eles pareciam entender, mas em grande medida aquilo resvalava por cima de suas cabeças sem conseguir chegar perto dos neurônios.

No curso de Educação Física percebi um grande desinteresse pela reflexão filosófica. Para mim, foi o curso onde o desinteresse se apresentou com mais força. E algo que achei estranho, e nunca entendi bem, esse desinteresse também apareceu no curso de Serviço Social.

Essas foram, dito de uma maneira muito geral, as minhas experiências nos cursos de graduação. Nos Mestrados e Doutorados - em Desenvolvimento Regional e em Letras - a experiência pedagógica foi bastante diferente. Vou falar mais da experiência que tive no curso de pós-graduação em Letras. É um curso muito bom, é da minha área, é do meu interesse, então eu me senti muito em casa. Trabalhei Epistemologia e Métodos de Pesquisa. Sempre dei mais força na Epistemologia do que nos Métodos de Pesquisa (risos). Na Epistemologia, eu trabalhei conceitos relacionados ao conhecimento e à linguagem; a questão dos paradigmas; as concepções a respeito da realidade, tais como o positivismo, a metafísica, a dialética; dialogismo, polifonia e carnavalização na literatura; literatura e ideologia e por aí.

Barbarói, Santa Cruz do Sul, n.59 - número especial, p.<174-193>, Ago./Set. 2021 
Gostei muito de trabalhar nos cursos de pós-graduação, tanto em Letras como em Desenvolvimento Regional. Neste último, também insisti bastante nas questões relacionadas ao conhecimento, de modo particular a questão da possível regionalização dos conhecimentos, que, fundamentalmente, são universais.

\section{Entrevistadores:}

Você contempla muitas questões relacionadas às Humanidades e ao lugar das Ciências Humanas na formação universitária.

\section{Sérgio Schaefer:}

Qual poderia ser o papel das Ciências Humanas na formação acadêmica? Penso que as diversas Ciências Humanas abrem perspectivas fundamentais na formação acadêmica. Em primeiro lugar, permitem que se compreenda a complexidade da realidade além dos estereótipos, dos preconceitos culturais e das amarras ideológicas que nos dominam e que foram introjetadas pela educação e pelo meio social e que são constantemente reforçadas de vários modos. A ruptura com estereótipos, com preconceitos e com visões ideológicas, no entanto, só acontece se os responsáveis pela formação acadêmica dos alunos tiverem, por sua vez, superado estereótipos, preconceitos e ideologias de dominação. Em segundo lugar, como consequência, as Ciências Humanas permitem desenvolver análises críticas da realidade. Criticar é, antes de tudo, ver com clareza alguma coisa, fazer com que o pensamento entre em crise, isto é, que se dê conta de que a realidade é diferente daquilo que se pensava a respeito dela. Em terceiro lugar, as Ciências Humanas permitem entrever mudanças, a possibilidade de mudanças. As mudanças, no meio social - em suas dimensões políticas, econômicas, culturais etc. - não são obrigatórias, são tão somente possíveis. Por isso, as Ciências Humanas não podem impor mudanças e, sim, propô-las, argumentando em seu favor. Um dos maiores problemas das Ciências Humanas é a tentação autoritária de imposição de mudanças.

\section{Entrevistadores:}

E esse instigar mudanças na Universidade? Nesse tempo em que você atuou como professor universitário você percebeu mudanças nesse sentido? A Universidade ganhou, perdeu, continuou com o mesmo espírito de provocação? Não raras vezes sentimos que há um processo de burocratização no trabalho universitário que se contrapõe a essa necessidade, de situar a formação universitária também como um "dizer de um modo diferente a necessidade de mudança”.

Barbarói, Santa Cruz do Sul, n.59 - número especial, p.<174-193>, Ago./Set. 2021 


\section{Sérgio Schaefer:}

Não me parece que é só a burocracia que está impedindo isso - apesar de ela contribuir para isso - são os próprios professores que estão impedindo isso. Percebi, nos últimos anos em que trabalhei na UNISC, nos últimos 5 ou 6 anos, de 2010 em diante (deixei a UNISC em 2016), algo significativo: muitos professores começaram a perder a capacidade de trabalhar a diferença. Começaram a insistir na semelhança. Bom, o que significa isso? Diferença e semelhança são dois conceitos muito importantes, pelo menos para mim. O conceito de semelhança significa, na pedagogia ou na didática, trabalhar conceitos já acumulados e estabelecidos. Então, o professor é um repetidor, ou seja, ele trabalha com a semelhança. O problema é que muitos professores começaram a perder, me parece, a capacidade de trabalhar a diferença. Quando você trabalha uma coisa pela diferença, você está, implicitamente, sugerindo a mudança.

Vou dar um exemplo: o movimento hippie. Quando começou o movimento de liberação, nos EUA e em outros países, os hippies simplesmente se apresentaram como diferentes. E nunca falaram "temos que fazer uma revolução, temos que mudar as estruturas dos EUA e do mundo". Nunca eles falaram. Eles simplesmente se apresentaram como diferentes, e isso foi um verdadeiro golpe na mesmidade americana. E do mundo. Ou seja, mostrar-se com cabelos compridos quando não era normal, mostrar-se com roupas displicentes, chinelos de dedos nos pés, sentados no chão, morando em barracas, isso foi tão diferente que os americanos se escandalizaram e várias estruturas sociais envelhecidas ficaram abaladas. O movimento hippie foi um impacto necessário para divulgar uma ideia da diferença.

Atenção. Não estou afirmando que a diferença produz automaticamente a mudança. Ela sugere. Ela dá a ideia de que algo pode mudar, se for o caso. As mudanças efetivas são fruto de alguma práxis.

Soube que a UNISC está em processo de reestruturação. Eu não tenho elementos suficientes para julgar o que está para acontecer com essas novidades, com essa reestruturação. É preciso deixar que ela primeiro aconteça na prática. Tomara que não seja apenas a colocação de roupa nova num corpo velho. Se a UNISC está apenas colocando roupa nova num corpo velho, a reestruturação será feita pela semelhança e apenas aparentemente estará sugerido mudanças. Ela continuará sendo a mesma coisa só que com outra imagem, outra coisa por fora. Não sei, tomara que não. Tomara que seja realmente uma diferença. Se for uma diferença, estou batendo palmas.

Penso que o Departamento de Ciências Humanas - ou aquilo em que ele vai se tornar com a reestruturação - é um dos principais nichos de provocação de mudanças no interior da Barbarói, Santa Cruz do Sul, n.59 - número especial, p.<174-193>, Ago./Set. 2021 
estrutura da universidade. Penso ainda que a Psicologia, a Pedagogia, História e Geografia e algum outro curso (não sei dizer qual) seriam interessantes promotores da diferença.

Tem a questão, então, do papel da Universidade, enquanto Instituição. Sendo coerente com minha reflexão, é pela diferença que a Universidade pode chegar a cumprir seu papel. O que isso significa? Significa que todo o conhecimento desencadeado nos níveis de graduação, da pós-graduação, das especializações e cursos de nível técnico, não pode ser apenas uma repetição de conhecimentos já estabelecidos. Mesmo sem esquecer o conhecimento acumulado, a Universidade precisa avançar nos conhecimentos.

Ora, avançar significa gerar novos conhecimentos. E estes novos conhecimentos não podem ficar guardados nas salas de aula e nos centros e núcleos de pesquisa da própria Universidade. Precisam reverter em benefícios para a sociedade. Em novos benefícios.

A geração de conhecimento para todos é um papel político? Sem dúvida, pois é democrático em suas bases. Todas as universidades, com seus centros de pesquisa, com seus mestres, doutores e pós-doutores, geram conhecimentos para todos? É uma boa pergunta. Teoricamente, os conhecimentos pertencem a todos. Na prática, eles beneficiam de um modo especial as minorias exploradoras, como é, entre outros, o caso brasileiro. Sabedora disso, pararia a Universidade de produzir novos conhecimentos? Não. Teria que se unir aos desfavorecidos e lutar junto com eles para que os conhecimentos e seus benefícios fossem democratizados.

Essa luta pela democratização dos conhecimentos e seus benefícios na sociedade é, certamente, a grande diferença que a Universidade pode gerar.

\section{Entrevistadores:}

Você nos contou um pouco sobre sua experiência recente de trabalhar com escolas de ensino básico. Ir conversar com os estudantes sobre temas da filosofia, da arte. Nos conte um pouco sobre essa experiência.

\section{Sérgio Schaefer:}

Uma professora do Ensino Fundamental de uma escola da minha cidade (Venâncio Aires) me convidou para discutir com alunos do sexto ao nono anos temas de Filosofia. Aceitei, com uma condição: que nossos encontros fossem na minha chácara, na Chácara das Corujas. Tudo acertado, os encontros começaram com 20 alunos ou um pouco mais de cada vez. Esses encontros foram muito interessantes, tanto para mim como para aquela gurizada e meninada.

Nossas "aulas" aconteciam caminhando pelos diversos ambientes da chácara. Por exemplo, quando discutimos o conceito binário semelhança/diferença fomos até o mato que existe na Barbarói, Santa Cruz do Sul, n.59 - número especial, p.<174-193>, Ago./Set. 2021 
parte norte da chácara e os alunos foram convidados a recolher diferentes tipos de folhas nos arbustos, nas árvores ou caídas no solo. O objetivo que eu queria alcançar era o seguinte: queria que aquelas meninas e aqueles meninos percebessem que a ideia de 'folha' (de árvore) era construída através da binariedade lógica da semelhança e da diferença. Folhas recolhidas, sentamos no chão em uma roda no coreto que tem ao lado da casa e todos foram convidados a ajeitar as folhas na sua frente. Pergunto: “Tem uma folha igual a outra?" Resposta deles: “Não, são todas diferentes”. Eu: “Apesar das diferenças, são todas folhas, não é?” Eles: "Sim." A partir desse momento, começo a me esforçar para deixar claro que um conceito (uma ideia) a respeito da realidade é construído por nós confrontando as diferenças e as semelhanças e que toda a vez que confrontamos o grupo conceitual já constituído com uma nova diferença, enriquecemos o conceito (ou a ideia). Ou seja, provocamos, pelo processo de abstração, uma mudança conceitual, que pode ser maior ou menor.

O importante, aqui, é perceber que a semelhança se faz pela diferença e é a diferença que enriquece a semelhança. Uma Universidade, por exemplo, só é 'universidade' por causa da diversidade, isto é, por causa da(s) diferença(s). Rejeitar a diferença é insistir na mesmidade, mesmo sabendo que a própria mesmidade, em algum momento, foi construída pelo confronto binário semelhança/diferença. O mesmo conceito 'árvore' usado para indicar todas as árvores foi constituído pela semelhança/diferença entre as árvores.

Voltando ao ponto. Além do tema da constituição dos conceitos (ideias) pelo confronto entre semelhança e diferença, trabalhei com os pequenos e jovenzinhos alunos o tema dos velhos saberes que vão sendo substituídos por novos saberes, o tema das aparências que enganam, o tema da felicidade e por aí. Aqueles meninos e meninas gostaram demais de nossos encontros. Com a chegada da pandemia do coronavírus, nossa bela experiência foi interrompida.

\section{Entrevistadores:}

O que pensa a respeito do método comparativo? Ele pode ajudar a entender a diferença?

\section{Sérgio Schaefer:}

O método comparativo já é indicativo da diferença. Cada área do saber precisa descobrir como é que vai colocar em destaque a diferença. O método comparativo permite captar a

diferença. É assim que a gente constrói, por exemplo, o conceito de 'árvore': comparando uma com a outra. Um bom método em Ciências Sociais é o método comparativo, porque ele faz com que a gente perceba a diferença. Ao comparar o rico com o pobre, podemos perceber $\mathrm{a}(\mathrm{s})$ diferença(s). Aliás, o conceito de riqueza só pode ser entendido em confronto com o conceito de pobreza. É um conceito binário.

Barbarói, Santa Cruz do Sul, n.59 - número especial, p.<174-193>, Ago./Set. 2021 


\section{Entrevistadores:}

$\mathrm{Na}$ Universidade também não é difícil encontrarmos trabalhos que através da comparação violentam a diferença.

\section{Sérgio Schaefer:}

Sim, é preciso ter cuidado com o uso da comparação. Ela pode ser manipulada. Quero dar um exemplo da história da Filosofia: Hegel. Esse filósofo trata com grande cuidado as relações existentes na realidade e, assim fazendo, trabalha no âmbito das comparações (pelo menos, num primeiro nível). Mas, à medida em que aprofunda sua discussão, ele vai sobrepondo (num processo complexo chamado Aufhebung) as diferenças em favor da identidade. Desse modo, ele deixa de lado a dialética e desemboca na metafísica (necessitária).

\section{Entrevistadores:}

Pensando em termos de desdobramentos, e essa é uma situação não necessariamente exclusiva da UNISC, você teme a diminuição ou o "cercamento" das humanidades no ambiente universitário?

\section{Sérgio Schaefer:}

As Ciências Humanas ou as Humanidades, ao longo da história, sempre passaram por ciclos de aceitação ou de rejeição. Em termos macro, os temas que as Ciências Humanas abordam, nesse momento, estão em evidência, mesmo que não no ambiente acadêmico de alguma universidade. Basta perceber as constantes discussões a respeito das fake news, do tema que se chamou de pós verdade, dos temas relacionados com a preservação do meio ambiente, do tema do racismo, do tema da violência etc. etc. São todos eles temas das Ciências Humanas e, no atual contexto, estão sendo discutidos de um de outro modo, mesmo que não academicamente. É bom lembrar que o bolsonarismo, no Brasil, é um tema das Ciências Humanas e, também, o antipetismo.

Em termos micro, ou seja, em alguma Universidade, é possível que haja o que vocês denominam "cercamento" em torno das Humanidades. Mesmo que a Universidade insista em esquecer os temas das Humanas, eles continuarão, por sua vez, cercando a universidade por todos os lados. Nesse caso, a universidade se torna uma ilha isolada do contexto. Aliás, o tema "ilha isolada do contexto social, político, cultural etc." é um dos temas das Ciências Humanas. Ou não? 


\section{Entrevistadores:}

No contexto do ensino universitário no Brasil, o que estamos vivenciando, desde os anos 1990, é um processo de privatização do ensino. E uma privatização que é conduzida a partir dos interesses de grandes grupos econômicos, que propõem uma formação universitária curta, voltada a supostas necessidades do mercado. Essa concepção, hoje, por exemplo, é expressa em muitas experiências de cursos na modalidade EaD. Você entende que, mesmo nessas condições, as ciências humanas sejam reconhecidas?

\section{Sérgio Schaefer:}

Não sou contra o Ensino a Distância. Do ponto de vista pedagógico, o EaD pode proporcionar índices de liberdade que o estrito ensino presencial não proporciona. Se for bem estruturado, bem desenvolvido, por pessoas conscientes, professores conscientes, universidades conscientes, e mesmo escolas de níveis fundamental e médio conscientes, o EaD pode desencadear a autonomia pessoal, a liberdade de pensamento e a criatividade com maior profundidade do que o ensino presencial. Entretanto, tudo indica que a maioria das propostas de $\mathrm{EaD}$ que atualmente estão em andamento não são índices de liberdade. Pelo contrário, são índices de dominação. Esse é o principal problema dos atuais cursos de $\mathrm{EaD}$ e também das estratégias de ensino a distância adotadas pelas escolas públicas e particulares de ensino fundamental e médio durante a pandemia do coronavírus.

O problema das Humanidades no EaD é o mesmo que acontece na Universidade. Percebe-se claramente que a tendência nos cursos de EaD é a de tratar temas das Humanas com superficialidade ou, mesmo, nem sequer dar chance de serem tratados. Tudo, para encurtar a formação universitária (ou outra), usando como argumento a necessidade que o mercado tem de mão de obra nos diversos setores da sociedade.

\section{Entrevistadores:}

Então, no seu entendimento, é possível formar um indivíduo no ambiente do EaD, com amadurecimento intelectual, amadurecimento de disciplina, todos esses indicadores que pressupõem maturidade intelectual de alguém?

\section{Sérgio Schaefer:}

Sim, penso que é possível. Mas também penso que uma proposta pedagógica melhor seria equilibrar o $\mathrm{EaD}$ com o ensino presencial. O papel presencial do professor nunca será substituído pela distância de algum sinal digital. A liberdade desencadeada presencialmente tem outro índice do que a liberdade proporcionada pela distância.

Barbarói, Santa Cruz do Sul, n.59 - número especial, p.<174-193>, Ago./Set. 2021 
O ensino presencial tem maior importância nos níveis do ensino fundamental e médio. Deveria ter, nesses níveis, maior peso e maior densidade, a fim de que a liberdade fosse bem encaminhada, o que terá grande relevância quando o aluno ingressar nos níveis superiores de ensino. A liberdade é um aprendizado.

\section{Entrevistadores:}

Pois é. Os dados existentes dizem que percentagens muito significativas de estudantes de licenciatura estão estudando na modalidade de EAD. E há uma voz crítica bastante elevada de que esse é um processo de desqualificação da formação dos professores.

\section{Sérgio Schaefer:}

Isso é fato, do modo como o EaD está sendo desencadeado. E não só de futuros professores, mas também de profissionais de vários tipos. Concordo. Mesmo assim, ele não deixa de ser uma esperança pedagógica. O problema, parece, não está nos conteúdos desenvolvidos ou propostos nos cursos de $\mathrm{EaD}$, que normalmente são repetição dos cursos presenciais, e, sim, o problema parece estar tanto nos alunos que não aprenderam a ser livres como nos professores que não entendem que EaD não é ensino presencial. EaD é assim: é um momento de liberdade de pensamento, mas apenas quando existem momentos de liberdade nos próprios conteúdos propostos.

O professor é um coordenador dessa liberdade. Um curso de EaD deveria ser um processo de libertação teórica e prática. Um curso de $\mathrm{EaD}$ precisa de alguém que coordena, que encaminha, que dá rumos e dicas. Junto com a aprendizagem dos conteúdos, esse alguém tem que ser aquele que está preocupado com a autonomia do aluno. A maturidade para a autonomia precisa ser o diferencial de qualquer curso de $\mathrm{EaD}$ ou de qualquer proposta de EaD.

\section{Entrevistadores:}

A UNISC contratou um grupo que conduz seus cursos na modalidade em EaD. Os cursos são organizados por esse grupo. Através de uma plataforma são disponibilizadas condições tecnológicas, as aulas estão prontas, os sistemas de avaliação estão prontos. A Universidade, inclusive, paga para melhorar o produto que ela comprou, pois em caso de erros detectados, os professores podem fazer ajustes. E os professores estão recebendo oito horas em disciplinas de sessenta horas.

Barbarói, Santa Cruz do Sul, n.59 - número especial, p.<174-193>, Ago./Set. 2021 


\section{Sérgio Schaefer:}

Pelo que vocês estão dizendo, a proposta atual de EaD da UNISC não é uma proposta, mas uma imposição. Isto tira a liberdade de o professor trabalhar conteúdos de um modo diferente daquele imposto. E também retira dele a responsabilidade pedagógica. O professor se torna um repetidor, alguém que redistribui algo já pronto.

Mas mesmo no interior de uma estrutura rígida é possível promover lampejos de liberdade. Entretanto, essa questão tem que ser discutida com calma e com a cabeça no lugar. EaD não é tão simples assim. Toda liberdade é complexa. Não existe liberdade simples. E, ainda, os aparatos tecnológicos e sua dinâmica usados no EaD serão, sem dúvida, daqui para frente, algo cada vez mais normal no ensino. Mas é bom lembrar que o professor, na educação formal, é a "tecnologia das tecnologias", como uma vez disse Demo.

\section{Entrevistadores:}

Você coloca um ponto de vista que seria muito positivo se colocado de forma mais ampla. Ou seja, você discute EaD a partir de uma ideia de liberdade, o que pouco se coloca. O que se observa é que a Universidade já entrou num modelo fechado.

\section{Sérgio Schaefer:}

O real problema, o ponto de partida dos atuais cursos de EaD implantados nas diversas universidades, é a redução de custos. Não é a liberdade, é a redução de custos. Esse é o problema. Não é um ponto de partida pedagógico. É um ponto de partida contábil, administrativo, econômico. Como vocês antes disseram: um professor que trabalha uma disciplina de 60 horas no EaD recebe 8 horas. Uma baita redução de custos, não acham?

Para repensar o EaD, é preciso deslocar a atenção para a questão fundamental da liberdade no ensino.

\section{Entrevistadores:}

O cotidiano ofusca.

\section{Sérgio Schaefer:}

Isso. Ele ofusca as ideias. Quem está encerrado - e muitas vezes sufocado - dentro de uma estrutura pode não conseguir deslocar-se para um novo ponto de vista. A tendência é ficar imerso na semelhança, impossibilitado de pensar a diferença. E não só de pensá-la, mas principalmente de aceitar a diferença e colocá-la em prática. 


\section{Entrevistadores:}

Mas para uma Universidade do tamanho da UNISC, com esse discurso de desenvolvimento regional, de vínculo comunitário, há espaço para esse sentimento positivo?

\section{Sérgio Schaefer:}

Pensar, aceitar e colocar em prática a diferença é mais do que um sentimento, é uma opção política, social e pedagógica para qualquer Universidade. E também para a UNISC, que, ao longo de sua existência, fez várias tentativas para se tornar um polo regional de diferenciação. Será que conseguiu? A resposta não é simples. Para encontrá-la, seria preciso analisar os saltos qualitativos que ela, como instituição universitária, ao longo do tempo, gerou nas diversas áreas do conhecimento, tais como nas áreas das Ciências Humanas, das Biológicas e da Saúde, das Engenharias, das Exatas, das Letras e das Línguas etc. Uma Universidade tem como responsabilidade não só tratar de conhecimentos acumulados na história da humanidade, mas de um modo especial criar novos conhecimentos, isto é, diferenciar os conhecimentos. As perguntas a serem feitas são essas: a UNISC conseguiu fazer isso? em que áreas sim e em que áreas não?

Por outro lado, aquilo que se consegue diferenciar dentro do ambiente universitário nem sempre dará bons resultados quando sair desse ambiente. Quero dar um exemplo. O curso de Pedagogia da UNISC se esforçou muito (sei disso, porque nele trabalhei por muitos anos como professor de Filosofia da Educação) para que seus alunos, na atuação em suas escolas, fossem professores diferentes. O que aconteceu na prática? Ao entrarem nas estruturas educacionais do Estado ou dos Municípios, ou voltarem para elas, eram pressionados para o retorno à semelhança, à mesmidade de antes. Quer dizer, o Estado exige que a ação pedagógica seja de um modo e, pronto, os professores são obrigados a atuar daquele modo. A diferenciação que aprenderam na universidade fica de lado.

\section{Entrevistadores:}

O que significa que a continuidade de estruturas como a UNISC não é outra coisa do que a reprodução do status quo. Ela tenta não ser isso, mas ela não alcança.

\section{Sérgio Schaefer:}

No caso de uma Universidade, reproduzir o status quo significa reproduzir basicamente o conhecimento acumulado, insistindo principalmente na semelhança dos conceitos. Não quero afirmar que a UNISC é apenas reprodutora de conhecimentos acumulados. Suponhamos que fosse. Daí sim, ela estaria contribuindo para que não acontecessem mudanças na sociedade. Uma boa pergunta a ser feita é a seguinte: estão acontecendo mudanças nos meios sociais de Barbarói, Santa Cruz do Sul, n.59 - número especial, p.<174-193>, Ago./Set. 2021 
influência da UNISC? Se essas mudanças estão acontecendo, então é possível que a Universidade esteja contribuindo de algum modo para a efetivação dessas mudanças.

\section{Entrevistadores:}

E, é claro, o que você está colocando também se refere à questão da identidade. Qual é a identidade da Universidade e como essa identidade se expressa na atuação dos profissionais que, afinal, fazem um curso universitário nela. E dai a questão: a UNISC tem uma identidade? Se tem, encontra dificuldades para tornar consequente essa identidade na educação dos estudantes?

\section{Sérgio Schaefer:}

Tudo tem uma identidade. A identidade de algo é constituída pela semelhança na diferença. A pergunta pela identidade de algo, portanto, deve ser feita pela diferença e não pela semelhança. Qual é a diferença da UNISC que constitui a sua identidade? Boa pergunta.

\section{Entrevistadores:}

A questão é que hoje, em conversas com diferentes pessoas de Santa Cruz do Sul, é possível perceber que alguns setores têm uma representação social da UNISC como uma "Universidade de Esquerda".

\section{Sérgio Schaefer:}

Vejam bem. A identificação da UNISC como "de esquerda" só é possível "pela direita", que é a diferença. São "setores" de direita que têm a representação social da UNISC como sendo (do verbo identitário 'ser') de esquerda. Do ponto de vista concreto, isso significa que nesses “setores” possíveis propostas de mudança por parte da Universidade não seriam aceitas.

\section{Entrevistadores:}

Sérgio. Muito obrigado pelo seu tempo, pelas suas reflexões. Nosso término não poderia ser diferente. Nossas perguntas sobre a identidade da Universidade não precisam ser respondidas. Que instiguem o pensar. 


\title{
PHILOSOPHY AND HUMANITIES IN UNIVERSITY FORMATION.
}

\begin{abstract}
:
The interview addresses topics such as the importance of philosophy and the humanities in university education. Based on a retrieval of the trajectory of Professor Sérgio Schaefer at the University of Santa Cruz do Sul, as a professor of Philosophy, the interview raises questions about the experience of building a community university, the struggles for the recognition of training spaces for the philosophy and human sciences in different areas of knowledge, about the challenges posed in times of technological changes and the affirmation of pragmatic paths in the field of education for thinking and doing philosophy at the University.
\end{abstract}

\section{Keywords:}

UNISC, university education, philosophy, humanities, philosophy and humanities at the University.

\section{Sobre os autores:}

Sérgio Schaefer é graduado em Filosofia, Mestre em Filosofia pela Pontifícia Universidade Católica do Rio Grande do Sul e Doutor em Letras pela Universidade Federal do Rio Grande do Sul. Foi professor na Universidade de Santa Cruz do Sul durante o período de 1982 a 2016, atuando em diversos cursos de graduação, em disciplinas de Filosofia, Epistemologia, Lógica, Ética. Ainda na UNISC atuou no Programa de Pós-Graduação (Mestrado e Doutorado) em Desenvolvimento Regional e no Programa de Pós-Graduação (Mestrado e Doutorado) em Letras.

César Hamilton Brito de Goes é graduado em Ciências Sociais, Mestre e Doutor em Sociologia pela Universidade Federal do Rio Grande do Sul (UFRGS). É Professor e Pesquisador na UNISC (Universidade de Santa Cruz do Sul), onde atua no Departamento de Humanidades, Ciências e Educação.

Marco André Cadoná é graduado em Filosofia, Mestre em Sociologia (Universidade Federal do Rio Grande do Sul) e Doutor em Sociologia Política (Universidade Federal de Santa Catarina). Professor e Pesquisador na UNISC (Universidade de Santa Cruz do Sul), onde atua no Departamento de Humanidades, Ciências e Educação e no Programa de Pós-Graduação em Desenvolvimento Regional. 